\title{
AVALIAÇÃO DO POTENCIAL DE PRODUÇÃO DE BIOGÁS E DA EFICIÊNCIA DE TRATÁMENTO DO REATOR ANAERÓBIO DE MANTA DE LODO(UASB) ALIMENTADO COM DEJETOS DE SUÍNOS
}

\author{
Potential evaluation of biogas production and treatment efficiency of an upflow anaerobic sludge \\ blanket (UASB) fed with swine manure liquid effluent
}

\author{
Cláudio Milton Montenegro Campos ${ }^{1}$, Emerson Teruaki Mochizuki², \\ Leonardo Henrique Soares Damasceno ${ }^{3}$, Cláudio Gouvêa Botelho ${ }^{4}$
}

\begin{abstract}
RESUMO
Com o presente trabalho de pesquisa objetivou-se avaliar a eficiência na remoção de poluentes orgânicos e a produção de biogás de um sistema de tratamento de efluentes de dejetos de suínos em escala laboratorial (bancada). A pesquisa foi desenvolvida no Laboratório de Análise de Água do Departamento de Engenharia (LAADEG) da Universidade Federal de Lavras (UFLA). O sistema de tratamento foi constituído por um Tanque de Acidificação e Equalização (TAE), Reator Anaeróbio de Manta de Lodo (UASB) com medidor de biogás (gasômetro) e uma Lagoa Aerada Facultativa (LAF). A alimentação foi realizada em bateladas no TAE, onde o efluente líquido era bombeado para um sistema de aquecimento sendo então introduzido no reator UASB e finalmente conduzido para polimento na LAF. O biogás acumulado na parte superior do UASB, após passar por um equalizador de pressão, era canalizado e armazenado no gasômetro. O valor médio do Tempo de Detenção Hidráulica (TDH) foi de 30 horas. Os valores médios de remoção da DQO $_{\text {T }}$ DBO $_{5}$ ST, STF e STV, foram: 1755, 670, 1089; 142 e 948 mg.L $L^{-1}$, respectivamente. As eficiências de remoção da DQO e $\mathrm{DBO}_{5}$ no reator UASB foram de 78 e $75 \%$, respectivamente. A produção média de biogás e metano $\left(\mathrm{CH}_{4}\right)$ foi de 0,14 e $0,10 \mathrm{~L} \cdot \mathrm{d}^{-1}$. O potencial de produção de $\mathrm{CH}_{4}$ em termos de $\mathrm{DBO}_{5}$ removida foi de $0,01 \mathrm{~m}^{3} \mathrm{CH}_{4} \cdot\left(\mathrm{kg} \text {. } \mathrm{DBO}_{\text {removida }}\right)^{-1}$. O sistema apresentou boa eficiência quanto a remoção de $\mathrm{DQO}_{\mathrm{T}}, \mathrm{DBO}_{5}$ e Sólidos.
\end{abstract}

Termos para indexação: Tratamento de efluentes, dejetos suínos, reator UASB, biogás.

\begin{abstract}
The present research aimed at evaluating in lab-scale system the removal of pollutants and biogas production efficiency in treating a swine liquid effluent. The research was carried out in the Laboratory of Water Analysis from the Engineering Department of Federal University of Lavras (LAADEG). The system parts built up were: Acidification Equalization Tank (AET), an Upflow Anaerobic Sludge Blanket reactor (UASB) with biogas measurement and an Aerated Facultative Pond (AFP). The batch feeding process was carried out in the AET, and through a peristaltic pump, the effluent passed through a heating system before it was introduced in the UASB reactor, only then, the effluent was conducted to the AFP. The biogas production was canalized to a pressurized container for equalization and then, kept in a water displacement gasmeter. The average hydraulic retention time (HRT) was 30 hours. The average removal values of $\mathrm{COD}_{\mathrm{T}}$, BOD , TS, TFS and TVS, were: 1755, 670, $1089 ; 142$ and 948 mg.L ${ }^{-1}$, respectively. The efficiency of $\mathrm{COD}_{\mathrm{T}}$ and $\mathrm{BOD}_{5}$, were 78 and $75 \%$, respectively. The average biogas and methane production were

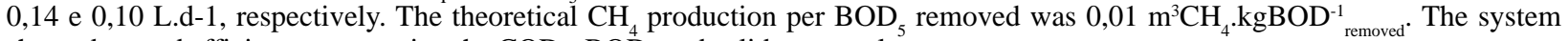
showed a good efficiency concerning the $\mathrm{COD}_{\mathrm{T}}, \mathrm{BOD}_{5}$ and solids removal.
\end{abstract}

Index terms: Effluent treatment, swine manure, UASB, biogas, methane.

(Recebido para publicação em 12 de dezembro de 2002 e aprovado em 6 de junho de 2005)

\section{INTRODUÇÃO}

Durante décadas acreditou-se que o crescimento econômico "per si" proporcionaria melhores condições de vida para a sociedade. Todavia, a partir da década de 60, em consequiência do ritmo acelerado da industrialização e o aumento da população, os impactos ao meio ambiente tornaram-se cada vez mais agravantes.

A atividade suinícola vem se destacando pela sua qualidade técnica e elevada produtividade, gerando boas relações econômicas na indústria, comércio, prestação de serviço e meio científico. No entanto, a viabilidade da atividade fica ameaçada quando se refere ao meio ambiente, sendo considerada pelos órgãos de controle ambiental, como de alto potencial poluente.

A concentração de Demanda Bioquímica de Oxigênio $\left(\mathrm{DBO}_{5}\right)$ dos dejetos de suínos chega a apresentar valores de até $52.000 \mathrm{mg} . \mathrm{L}^{-1}$, enquanto no esgoto humano a $\mathrm{DBO}_{5}$ é cerca de 200 a $300 \mathrm{mg}$. L-1 (OLIVEIRA, 1993). O suíno é um animal monogástrico e aproximadamente $30 \%$ dos seus alimentos tornam-se dejetos (fezes, urina e água de manejo). O desenvolvimento da suinocultura no Brasil

\footnotetext{
${ }_{1}^{1}$ Professor PH.D. Adjunto do Departamento de Engenharia da Universidade Federal de Lavras/UFLA - Caixa Postal 3037 - 37.200-000 - Lavras, MG. 2 Engenhiro Agrícola pela Universidade Federal de Lavras/UFLA.

${ }^{3}$ Engenheiro Agrícola pela Universidade Federal de Lavras/UFLA

${ }^{4}$ Professor M.Sc. Adjunto do Departamento de Engenharia da Universidade Federal de Lavras/UFLA.
} 
nos últimos anos passou de 26,5 milhões em 1993 para 37,7 milhões de cabeças em 2001 (ABIPECS, 2002). O volume de dejetos pode ser determinado em função do tamanho do rebanho e das práticas de manejo. Juntamente com o aumento do rebanho e da produtividade, surgem os problemas decorrentes da produção de dejetos e a qualidade ambiental.

No Brasil, a lei de Crimes Ambientais e a do Gerenciamento dos Recursos Hídricos, com atuação do Ministério Público na fiscalização da poluição no meio urbano e rural, vêm estabelecendo metodologias de fiscalização das bacias hidrográficas no controle de impactos ambientais o que tem levado a interdição de algumas granjas.

Com as reflexões em torno do meio ambiente, os consumidores estão cada vez mais conscientes, dando preferência a produtos ecologicamente corretos com certificados da ISO 14000 (Selo Verde, Agricultura Orgânica, etc). Os empreendedores financeiros não estão mais arriscando negócios ambientalmente incorretos e a própria sociedade vem exigindo ações dos órgãos competentes para o tratamento dos dejetos, bem como a punição dos infratores.

Portanto, devem ser buscadas soluções para enquadrar os criadores a essas normas emergentes, aonde os rótulos de produtos ecológicos e o impacto ambiental vêm ocupando lugar de destaque. Porém, sem mecanismos adequados de tratamento de dejetos de suínos, não há como conferir aos cursos d'água onde normalmente são destinados os efluentes, características adequadas de acordo com as normas de qualidade das águas especificadas pela legislação em vigor (CONAMA, 1990). Muitas vezes ocorre também, que os níveis de tratamento exigidos pela legislação, se tornam incompatíveis com a real situação econômica do produtor.

Uma das formas de tratamento de dejetos de suínos é a utilização de sistemas anaeróbios, que em comparação aos sistemas aeróbios, possui baixo consumo energético, baixa produção de sólidos e produção de biogás (CAMPOS et al., 1999). O Reator Anaeróbio de Manta de Lodo (UASB) tem apresentado um grande avanço tecnológico e de grande aceitação (CAMPOS, 1998; CAMPOS et al., 2003). O reator UASB além de possuir simplicidade construtiva e baixo custo operacional é capaz de suportar altas cargas orgânicas e produzir como sub-produto o biogás, composto rico em metano - $\mathrm{CH}_{4}$, (CAMPOS, 1990). O biogás pode ser utilizado em motores de combustão interna, iluminação, aquecimento, etc. O biogás pode, portanto, ser um bom combustível alternativo, substituindo o GLP, querosene, óleo diesel e energia elétrica (CAMPOS 1999). Sua composição em volume varia de 60 a $70 \%$ de metano $\left(\mathrm{CH}_{4}\right), 30$ a $40 \%$ de dióxido de carbono $\left(\mathrm{CO}_{2}\right), 0-3 \%$ nitrogênio $\left(\mathrm{N}_{2}\right), 0-1 \%$ de Hidrogênio $\left(\mathrm{H}_{2}\right), 0-1 \%$ de Oxigênio $\left(\mathrm{O}_{2}\right)$ e $0-1 \%$ de gás sulfídrico $\left(\mathrm{H}_{2} \mathrm{~S}\right)$ (SILVA, 1998).

O potencial energético dos dejetos de suínos é de $0,50 \mathrm{~m}^{3}$.biogás. $\mathrm{m}^{-3}$ de dejetos (KONZEN, 1983), sendo que, $1 \mathrm{~m}^{3}$ de biogás equivale a 0,66 litros de óleo diesel ou 0,7 litros de gasolina (OLIVEIRA, 1993). Contudo, deve-se levar em conta a corrosão provocada pela presença de $\mathrm{H}_{2} \mathrm{~S}$ (gás sulfídrico), o que leva a cuidados especiais, inclusive com o aumento de custos quando da concepção e manutenção de sistemas de reaproveitamento, devido a menor vida útil dos equipamentos normalmente utilizados (CAMPOS, 1999).

Em face ao exposto, objetivou-se com este trabalho de pesquisa avaliar, em escala laboratorial, o tratamento anaeróbio de efluentes de suinocultura, utilizando um Reator Anaeróbio de Manta de Lodo (UASB), visando investigar a eficiência do sistema proposto na transformação da matéria orgânica em biogás, a fim de se obter não apenas a minimização do efeito poluidor, mas ainda parâmetros de operacionalização do sistema implantado com vistas ao aproveitamento energético do biogás produzido.

\section{MATERIALEMÉTODOS}

O experimento foi realizado no Laboratório de Análise de Água do Departamento de Engenharia (LAADEG) da Universidade Federal de Lavras (UFLA). A coleta de dados se deu num período de 582 dias. Os dejetos de suínos (estrume, urina e água de limpeza do confinamento) utilizados na pesquisa, foram coletados nas instalações do Setor de Suinocultura do Departamento de Zootecnia (DZO) da UFLA.

O sistema foi constituído de um Tanque de Acidificação e Equalização (TAE), Reator Anaeróbio de Manta de Lodo (UASB), Lagoa Aerada Facultativa (LAF) e Gasômetro, cujos volumes eram de: 38; 11,7; 16 e 16 litros, respectivamente. $\mathrm{O}$ desenho esquemático pode ser visualizado nas Figuras 1 e 2.

$\mathrm{O}$ efluente sem qualquer tratamento preliminar era colocado no TAE, e posteriormente bombeado para o reator UASB, sendo aquecido antes de ser introduzido no mesmo utilizando sistema de serpentina submerso em água aquecida por resistência elétrica e com temperatura fixada por termostato. Em seguida o afluente era conduzido para 


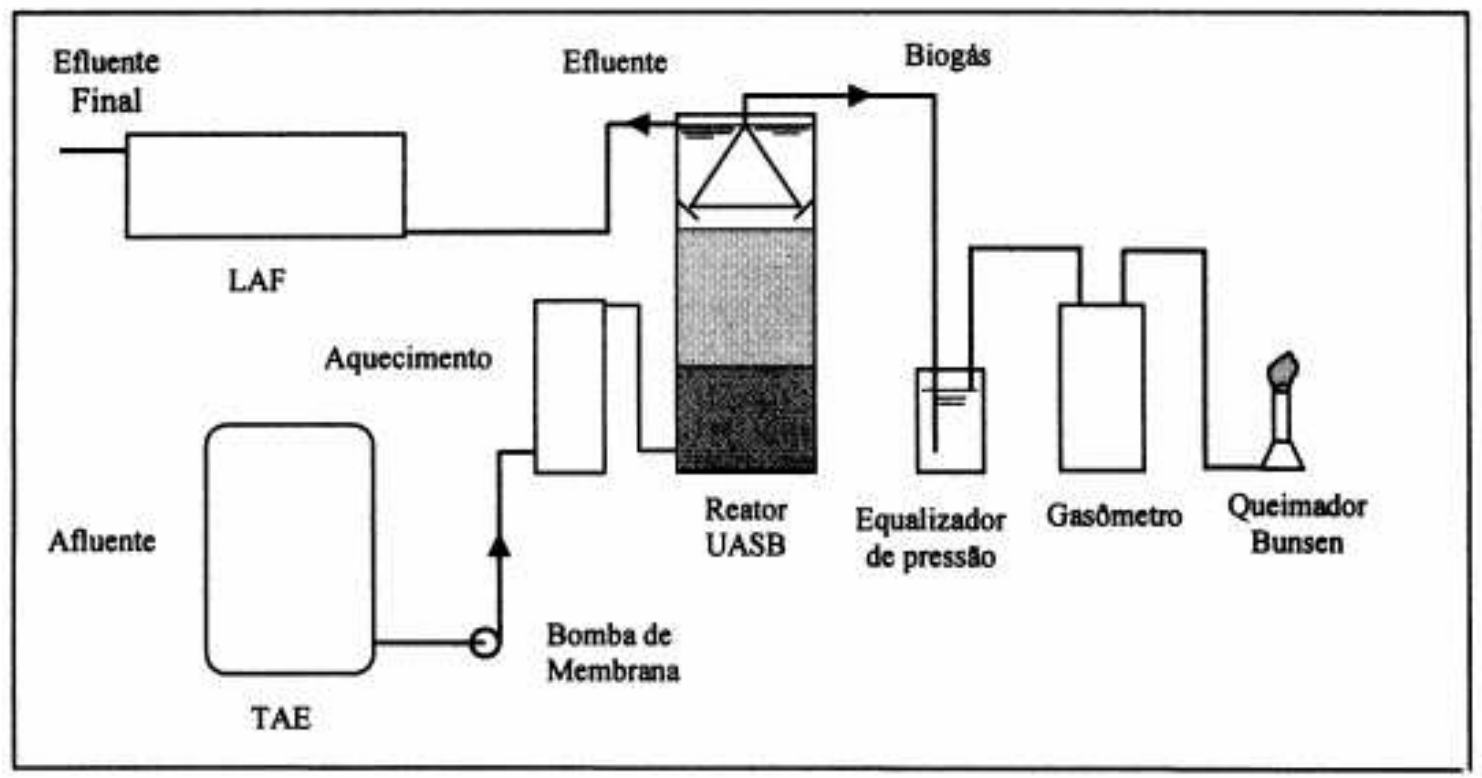

FIGURA 1 - Desenho esquemático do sistema laboratorial de tratamento.

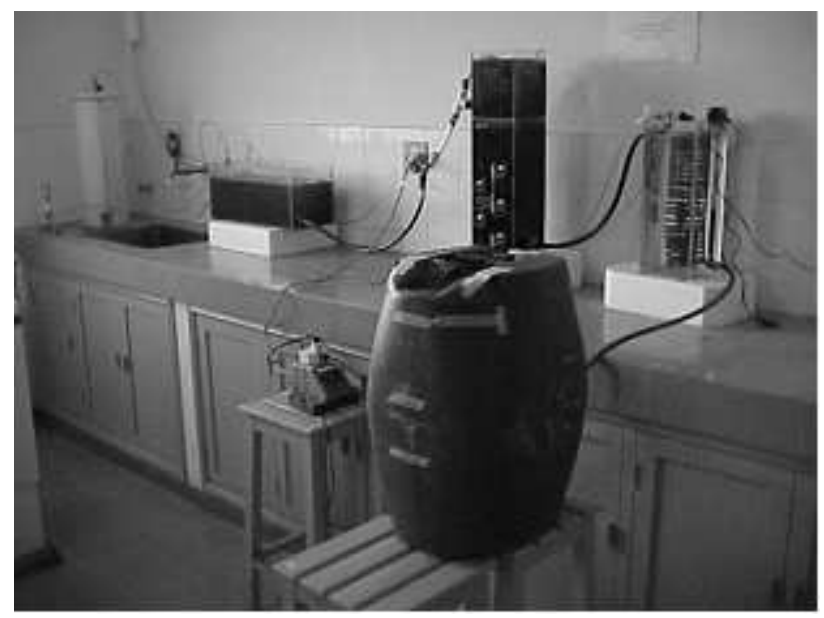

FIGURA 2 - Unidades do sistema de tratamento. 
a LAF a fim de ser polido. O biogás produzido era coletado na parte superior do UASB, no separador de três fases (sólido-líquido-gás), cujo nível de biogás, no seu interior, era regulado por um equalizador de pressão hermeticamente fechado. O biogás era então introduzido no gasômetro para ser armazenado e deste ao bico de bunsen para ser queimado. O processo de medição do biogás no gasômetro era realizado por deslocamento líquido.

Os valores de $\mathrm{CH}_{4}$ foram baseados na composição em volume de biogás de acordo com Silva (1998) e estimados teoricamente, baseando-se na relação teórica $0,35 \mathrm{~m}^{3} \mathrm{CH}_{4}$. (kg.DBO removida $)^{-1}$ considerando condições normais de temperatura e pressão (METCALF \& EDDY, 1995).

Com exceção do TAE, fabricado em plástico, os demais componentes foram construídos de vidro de $3 \mathrm{~mm}$.

A alimentação do sistema foi realizada com a utilização de uma bomba de membrana, marca MUELLER, modelo - FCO 0107PCSV, sendo sua faixa de vazão de 0,1 a 12 L.h $^{-1}$.

O monitoramento do sistema foi realizado por meio de parâmetros físico-químicos, sendo determinados: $\mathrm{pH}$, alcalinidade, vazão, temperatura, produção de biogás, $\mathrm{DQO}_{\mathrm{T}}, \mathrm{DBO}_{5}$, Sólidos Totais (ST), Sólidos Totais Fixos (STF) e Sólidos Totais Voláteis (STV). As análises foram realizadas de acordo com o APHA (1998). As medições de $\mathrm{pH}$, vazão, temperatura e produção de biogás foram realizadas diariamente, enquanto as análises de $\mathrm{DQO}_{\mathrm{T}}$, $\mathrm{DBO}_{5}$ e Sólidos, foram realizadas nos dias de recarga do sistema, aproximadamente de 4 em 4 dias. O Tempo de Detenção Hidráulica (TDH) adotado foi de 30 horas e a temperatura estabelecida no reator UASB de $25 \pm 2^{\circ} \mathrm{C}$.

\section{RESULTADOSE DISCUSSÃO}

O sistema operou por um período de 582 dias, mas neste trabalho foram considerados apenas 195 dias, a partir do $138^{\circ}$ até o $387^{\circ}$ dia, durante os quais foi dado maior enfoque à produção de biogás. O TDH algumas vezes sofria variações devido à alta concentração de sólidos presentes na bomba, os quais contribuíam para a diminuição da vazão. O TDH oscilou entre 13 e 59 horas, com valor médio de 30 horas; e a vazão média no sistema foi de $0,385 \mathrm{~L} . \mathrm{h}^{-1}$, com valor mínimo de $0,20 \mathrm{~L} \cdot \mathrm{h}^{-1}$ e máximo de $0,90 \mathrm{~L} \cdot \mathrm{h}^{-1}$. O pH médio afluente e efluente do reator UASB foi de 7,3, demonstrando bom tamponamento do sistema, o que contribuiu positivamente para o desenvolvimento de bactérias (CHERNICHARO, 1997). A temperatura no reator sofreu um pouco da influência das condições climáticas externas, apresentando valor médio de $25^{\circ} \mathrm{C}$.

As médias da $\mathrm{DQO}_{\mathrm{T}}$ afluente e efluente do reator UASB foram 1755 e 379 mg.L $\mathrm{L}^{-1}$, respectivamente, com eficiência média na remoção de $78 \%$. As variações da $\mathrm{DQO}_{\mathrm{T}}$ afluentes e efluentes no reator UASB podem ser visualizadas nas Figuras 3 e 4. A Carga Orgânica Volumétrica (COV) apresentou valor médio de $1,42 \mathrm{kgDQO}_{\mathrm{T}} \cdot \mathrm{m}^{-3} \cdot \mathrm{d}^{-1} \cdot \mathrm{As}$ variações podem ser atribuídas ao excesso de sólidos no sistema.

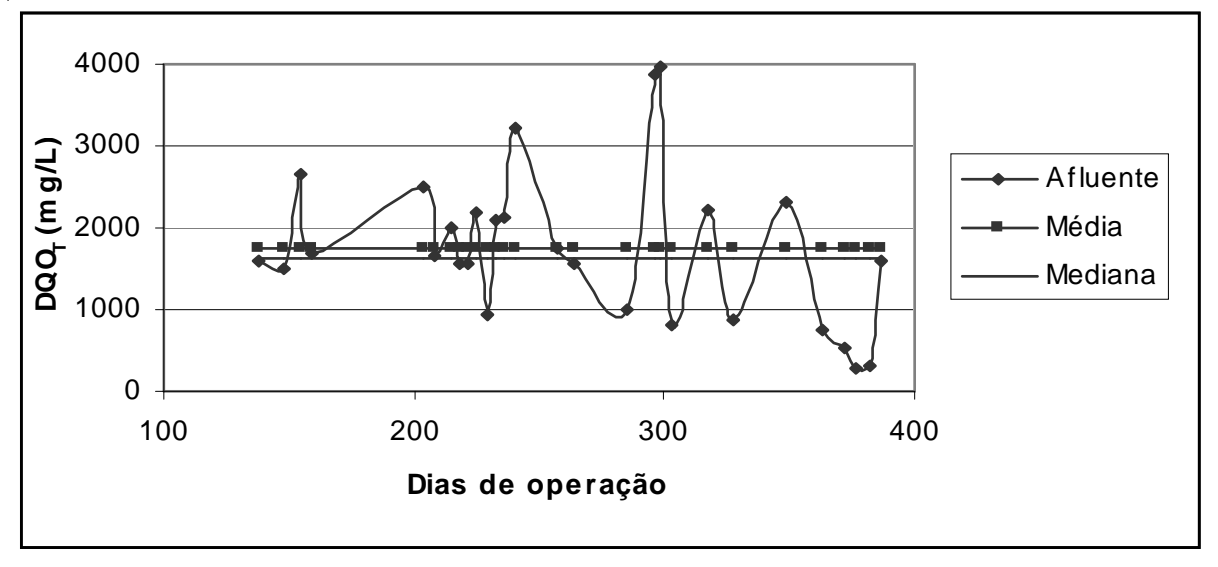

FIGURA 3 - Variação da $\mathrm{DQO}_{\mathrm{T}}$ afluente ao reator UASB. 
A $\mathrm{DBO}_{5}$ afluente ao reator UASB apresentou grandes variações, certamente devido as oscilações oriundas da composição dos dejetos e sua diluição. A pequena variação na $\mathrm{DBO}_{5}$ efluente do reator UASB demonstrou boa estabilidade do processo com eficiência na ordem de $75 \%$. A concentração de $\mathrm{DBO}_{5}$ afluente ao reator UASB apresentou valores entre 186 e $1632 \mathrm{mg} . \mathrm{L}^{-1}$, com valor médio de $838 \mathrm{mg}$. $\mathrm{L}^{-1}$. Já a concentração da $\mathrm{DBO}_{5}$ efluente do reator UASB apresentou valor médio de 168 mg. $\mathrm{L}^{-1}$. As variações da $\mathrm{DBO}_{5}$ podem ser visualizadas na Figura 5. Observando o gráfico dos valores da $\mathrm{DBO}_{5}$ afluente e efluente, nota-se que a média foi influenciada pelos valores extremos, como demonstra a mediana, cujo valor afluente e efluente foi de 780 e $144 \mathrm{mg} . \mathrm{L}^{-1}$, respectivamente. Os valores centrais do afluente foram de 473 e $1243 \mathrm{mg} . \mathrm{L}^{-1}$, e do efluente de 100 e $238 \mathrm{mg} . \mathrm{L}^{-1}$.

$\mathrm{O}$ volume de biogás produzido foi influenciado pela variação de pressão causada pela altura da coluna d'água do sistema de armazenamento. Ressalta-se ainda que ocorreram perdas de biogás no separador de três fases, em especial dos gases $\mathrm{CO}_{2}$ e $\mathrm{CH}_{4}$, cuja concentração no meio líquido era dependente da temperatura e da pressão parcial, segundo a Lei de Henry. Haandel \& Lettinga (1994) relatam perdas de $\mathrm{CO}_{2}$ e $\mathrm{CH}_{4}$ tanto no efluente líquido como para a atmosfera. Este fato fez com que a produção de biogás medido fosse menor do que aquela prevista teoricamente com base em considerações estequiométricas, resultando em medições práticas com valores abaixo de 20 a 50\%, da produção teórica.

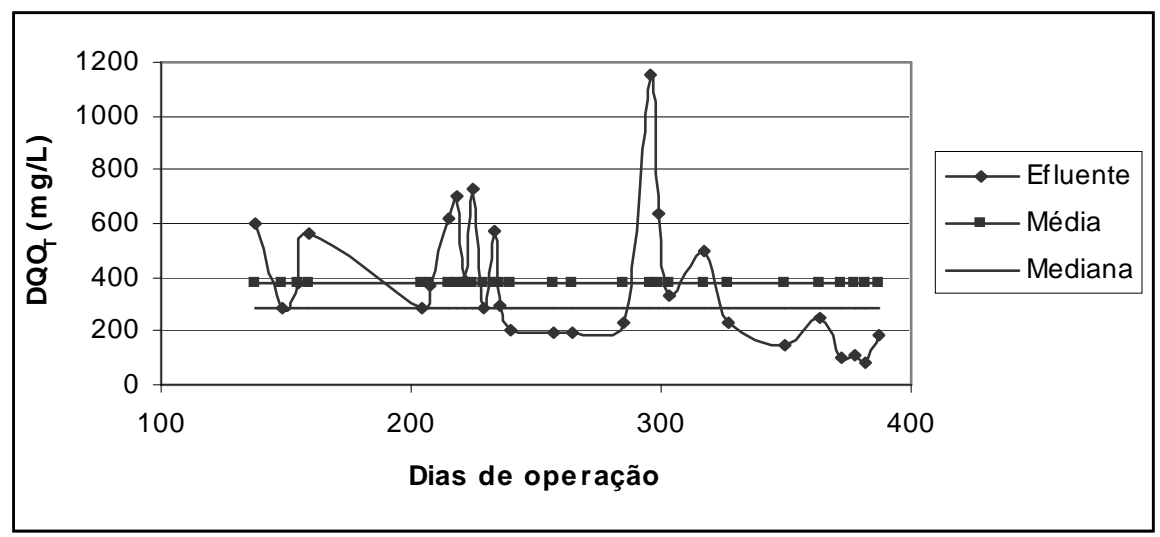

FIGURA 4 - Variação da $\mathrm{DQO}_{\mathrm{T}}$ efluente ao reator UASB.

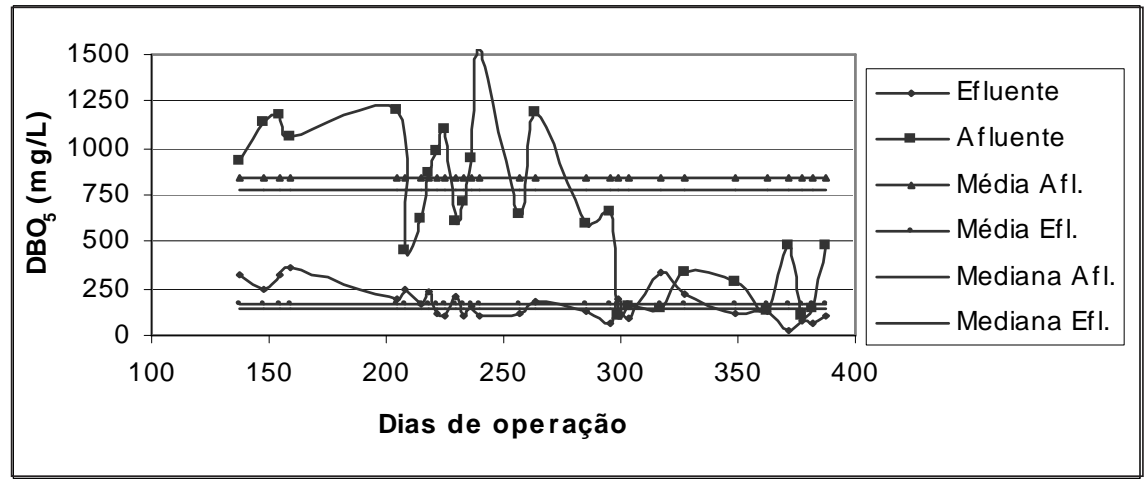

FIGURA 5 - Variação da $\mathrm{DBO}_{5}$ no reator UASB.

Ciênc. agrotec., Lavras, v. 29, n. 4, p. 848-856, jul./ago., 2005 
A produção de biogás apresentou valor mínimo de 0,03 L.d ${ }^{-1}$ e máximo de 0,36 L.d ${ }^{-1}$, com valor médio de 0,14 L.d ${ }^{-1}$. A grande oscilação da produção de biogás foi devido ao gasômetro, uma vez que, o deslocamento da coluna d'água, ficava sujeita as flutuações da pressão interna e da temperatura ambiente. Nota-se pela Figura 6 que a produção média de biogás foi influenciada pelos valores extremos. Já a mediana apresentou valor bem distinto em

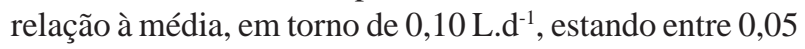
e $0,24 \mathrm{~L} \cdot \mathrm{d}^{-1}$ os valores centrais.

A composição química do biogás é basicamente de
60 a $70 \%$ de Metano $\left(\mathrm{CH}_{4}\right)$ e 30 a $40 \%$ de Dióxido de Carbono $\left(\mathrm{CO}_{2}\right)$ (SILVA, 1998). A produção teórica de $\mathrm{CH}_{4}$ apresentou valores compreendidos entre 0,02 e $0,25 \mathrm{~L}^{-d^{-1}}$,

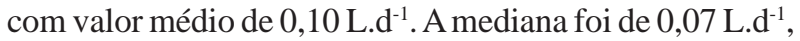
sendo os valores centrais de 0,04 e $0,17{\mathrm{~L} . \mathrm{d}^{-1}}^{\text {, o que }}$ demonstrou que os valores extremos influenciaram na média.

Os valores médios, mínimos, máximos, medianas, desvios-padrão e coeficientes de variação, obtidos no experimento, bem como as citações de outros autores estão listadas na Tabela 1.

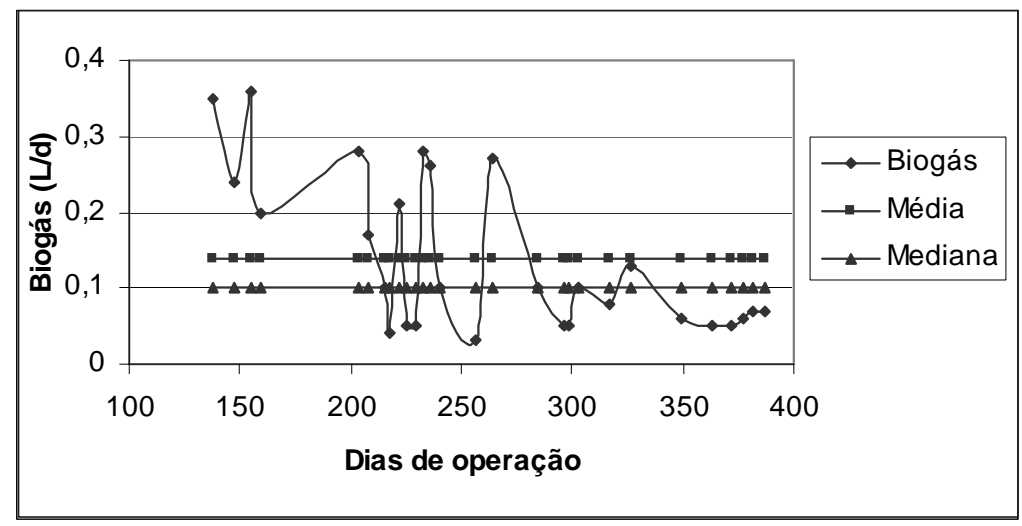

FIGURA 6 - Produção de biogás no reator UASB.

TABELA 1 - Parâmetros analisados no sistema.

\begin{tabular}{|c|c|c|c|c|c|c|c|}
\hline \multicolumn{2}{|c|}{ Análises } & Mínimo & Máximo & Média & Mediana & $\begin{array}{l}\text { Desvio } \\
\text { Padrão }\end{array}$ & $\begin{array}{c}\text { Coef. de } \\
\text { Variação }\end{array}$ \\
\hline \multirow{3}{*}{$\begin{array}{l}\mathrm{DQO}_{\mathrm{T}} \\
(\mathrm{mg} . \mathrm{L})\end{array}$} & Afluente & 293 & 3980 & 1755 & 1628 & 938 & 0,53 \\
\hline & Efluente & 86 & 1157 & 379 & 290 & 244 & 0,64 \\
\hline & Removida & 182 & 3342 & 1376 & 1324 & 817 & 0,59 \\
\hline \multirow{3}{*}{$\begin{array}{c}\mathrm{DBO}_{5} \\
(\mathrm{mg} . \mathrm{L})\end{array}$} & Afluente & 186 & 1632 & 838 & 780 & 440 & 0,53 \\
\hline & Efluente & 360 & 30 & 168 & 90 & 144 & 0,53 \\
\hline & Removida & 103 & 1523 & 670 & 637 & 409 & 0,61 \\
\hline \multicolumn{2}{|c|}{ Biogás $\left(L . d^{-1}\right)$ - real } & 0,03 & 0,36 & 0,14 & 0,10 & 0,10 & 0,75 \\
\hline \multicolumn{2}{|c|}{$\mathrm{CH}_{4}{ }^{1}\left(\mathrm{~L} . \mathrm{d}^{-1}\right)-$ real } & 0,02 & 0,25 & 0,10 & 0,07 & 0,07 & 0,75 \\
\hline \multicolumn{2}{|c|}{$\mathrm{CH}_{4}{ }^{2}\left(\mathrm{~L} \cdot \mathrm{d}^{-1}\right)-$ teórico } & 0,07 & 0,96 & 0,42 & 0,40 & 0,26 & 0,61 \\
\hline \multicolumn{2}{|c|}{ Biogás ${ }^{2}\left(\mathrm{~L} \mathrm{~d}^{-1}\right)$ - teórico } & 0,08 & 1,25 & 0,55 & 0,52 & 0,33 & 0,61 \\
\hline \multicolumn{2}{|c|}{$\mathrm{CH}_{4}\left(\mathrm{~m}^{3} \mathrm{CH}_{4} \cdot \mathrm{kgDQO}^{-1}{ }_{\mathrm{rem}}\right)-$ real } & 0,001 & 0,021 & 0,01 & 0,01 & 0,01 & 0,72 \\
\hline \multicolumn{2}{|c|}{$\mathrm{CH}_{4}{ }^{3}\left(\mathrm{~m}^{3} \mathrm{CH}_{4} \cdot \mathrm{kgDQO}^{-1}{ }_{\text {rem }}\right)$ - teórico } & 0,10 & 0,18 & 0,14 & 0,14 & - & - \\
\hline
\end{tabular}

${ }^{1}$ Silva et al.

${ }^{2}$ Metcalf \& Eddy (1995);

${ }^{3}$ Oliveira, 2001 
Segundo Metcalf \& Eddy (1995), o cálculo teórico de $\mathrm{CH}_{4}$ pode ser obtido pela conversão da $\mathrm{DBO}_{5}$ :

- Taxa de produção de metano: $0,35 \mathrm{~m}^{3} \mathrm{CH}_{4} \cdot\left(\mathrm{kgDBO}_{\text {removida }}\right)^{-1}$; Pressão: 1 atm e temperatura de $20^{\circ} \mathrm{C}$.

- Carga Orgânica $\left(\mathrm{kg} \cdot \mathrm{d}^{-1}\right)=\mathrm{DBO}_{\text {removida }}\left(\mathrm{kg} \cdot \mathrm{m}^{-3}\right)$. Vazão $\left(\mathrm{kg} \cdot \mathrm{m}^{-3}\right)$ Produção de $\mathrm{CH}_{4}\left(\mathrm{~m}^{3} \mathrm{CH}_{4} \cdot(\mathrm{kg} \cdot \mathrm{DBO} \mathrm{removida})^{-1} \mathrm{~d}^{-1}\right)$ $0,35 \mathrm{~m}^{3} \mathrm{CH}_{4}{ }^{*}$ Carga Org. $\left(\mathrm{kg} \cdot \mathrm{d}^{-1}\right) \cdot 1,0 \mathrm{KgDBO}$

- Fórmula Barométrica:

$$
\mathrm{P}=\mathrm{P}_{0} \times \mathrm{e}^{-\frac{\mathrm{M} . \mathrm{g} . \mathrm{z}}{\mathrm{R} . \mathrm{T}}}
$$

Em que:

$\mathrm{P}=$ Pressão estática (atm);

$\mathrm{P}_{0}=$ Pressão atmosférica ao nível do mar (atm);

$\mathrm{M}=$ Massa molar média do ar atmosférico $\left(0,029 \mathrm{~kg} \cdot \mathrm{mol}^{-1}\right)$; $\mathrm{g}=$ Constante gravitacional $\left(\mathrm{m} \cdot \mathrm{s}^{-2}\right)$;

$\mathrm{z}=$ Altitude local $(\mathrm{m})$;

$\mathrm{R}=8,31441$ Pa. $\mathrm{m}^{3} \cdot\left(\mathrm{mol} . \mathrm{K}^{\mathrm{o}}\right)^{-1}$;

$\mathrm{T}=$ temperatura $\left(\mathrm{K}^{\circ}\right)$

- Equação do Gás ideal:

$$
\frac{P_{1 \times} V_{1}}{T_{1}}=\frac{P_{2 \times} V_{2}}{T_{2}}
$$

Em que:

$\mathrm{P}_{1}=$ Pressão atmosférica inicial (atm);

$\mathrm{V}_{1}=$ Volume inicial $\left(\mathrm{L} \mathrm{CH}_{4} \cdot \mathrm{d}^{-1}\right)$;

$\mathrm{T}_{1}=$ Temperatura inicial $\left(\mathrm{K}^{\circ}\right)$;

$\mathrm{P}_{2}=$ Pressão atmosférica final (atm);

$\mathrm{V}_{2}=$ Volume final $\left(\mathrm{L} \cdot \mathrm{CH}_{4} \cdot \mathrm{d}^{-1}\right)$;

$\mathrm{T}_{2}=$ Temperatura final $\left(\mathrm{K}^{\circ}\right)$.
Os valores teóricos de $\mathrm{CH}_{4}$ calculados segundo as equações descritas anteriormente, apontam para valores mínimo e máximo de $0,07 \mathrm{~L} \cdot \mathrm{d}^{-1} \mathrm{e} 0,96 \mathrm{~L} \cdot \mathrm{d}^{-1}$, respectivamente, com valor médio de $0,42 \mathrm{~L} \cdot \mathrm{d}^{-1}$. A produção teórica de biogás apresentou valores entre 0,08 e $1,25 \mathrm{~L}^{-\mathrm{d}^{-1}}$, com valor médio de $0,55 \mathrm{~L} \cdot \mathrm{d}^{-1}$. A variação da produção de biogás e $\mathrm{CH}_{4}$ pode ser visualizada na Figura 7.

Observa-se que a produção real de $\mathrm{CH}_{4}$ foi bem inferior ao determinado pela equação proposta pelos autores com base na $\mathrm{DBO}_{5}$. Essa diferença, já explicada anteriormente, foi em função da metodologia de medição empregada, a qual permitia grandes variações da pressão e temperatura, além da solubilização do biogás no líquido efluente.

A produção de $\mathrm{CH}_{4}$ em termos de $\mathrm{DQO}$ removida, apresentou valor mínimo e máximo de 0,001 e 0,02 $\mathrm{m}^{3} \mathrm{CH}_{4} \cdot\left(\mathrm{kgDQO}_{\text {removida }}\right)^{-1}$ respectivamente, com valor médio de $0,01 \mathrm{~m}^{3} \mathrm{CH}_{4} \cdot\left(\mathrm{kgDQO}_{\text {removida }}\right)^{-1}$ A mediana foi de 0,01 $\mathrm{m}^{3} \mathrm{CH}_{4} \cdot\left(\mathrm{kgDQO}_{\text {removida }}\right)^{-1} \mathrm{e}$ os valores centrais ficaram entre 0,003 e $0,01 \mathrm{~m}^{3} \mathrm{CH}_{4} \cdot\left(\mathrm{kgDQO}_{\text {removida }}\right)^{-1} \mathrm{O}$ valor da mediana foi idêntico ao valor da média, demonstrando simetria. A variação da produção de $\mathrm{CH}_{4}$ em termos de $\mathrm{DQO}$ removida pode ser visualizada na Figura 8.

Em trabalho realizado por Oliveira (1997), a eficiência na remoção de DQO foi de $72 \%$ e a produção específica de metano variou de $0,10 \mathrm{a} 0,18 \mathrm{~m}^{3} \mathrm{CH}_{4} \cdot\left(\mathrm{kgDQO}_{\text {removida }}\right)^{-1} \mathrm{com}$ valor médio de $0,14 \mathrm{~m}^{3} \mathrm{CH}_{4} \cdot\left(\mathrm{kgDQO}_{\text {removida }}\right)^{-1}$.

Nota-se que a produção de $\mathrm{CH}_{4}$, em termos de $\mathrm{DQO}_{\text {removida }}$, mostrou-se bem menor que aquela apresentada por Oliveira (1997), o que nos leva a concluir que a metodologia de leitura do volume de biogás produzido, utilizando metodologia de deslocamento líquido apresentou pouca precisão.

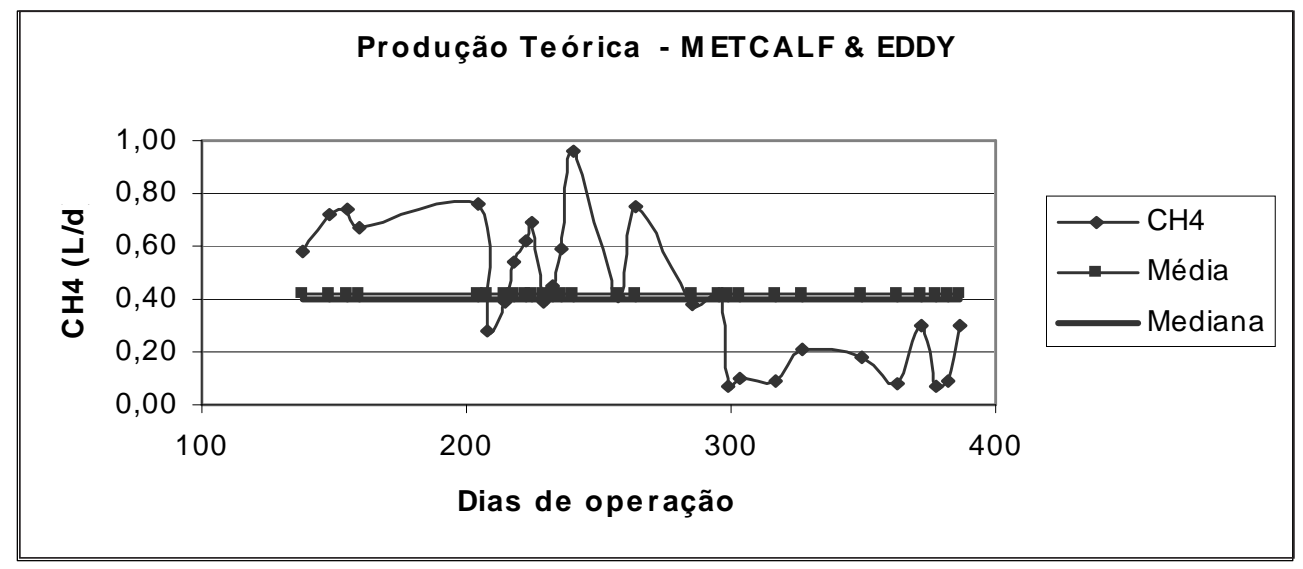

FIGURA 7 - Produção teórica de biogás e CH4 no reator UASB.

Ciênc. agrotec., Lavras, v. 29, n. 4, p. 848-856, jul./ago., 2005 


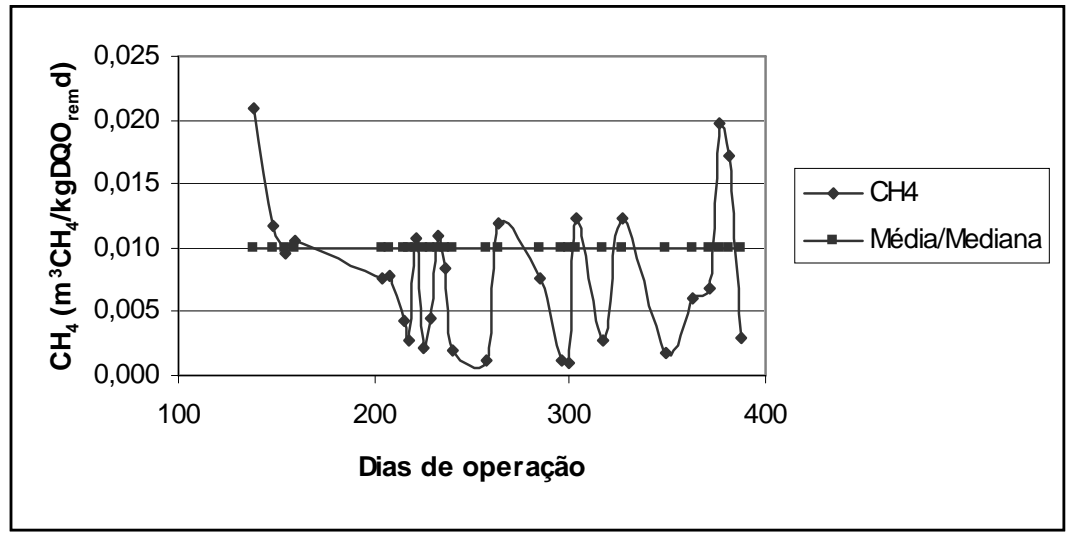

FIGURA 8 - Variação de produção de $\mathrm{CH}_{4}$ em termos de $\mathrm{DQO}_{\text {removida }}$ no UASB.

\section{CONCLUSÕES}

$\mathrm{O}$ reator UASB apresentou boa eficiência na remoção de $\mathrm{DQO}_{\mathrm{T}}(78 \%)$ e $\mathrm{DBO}_{5}(75 \%)$, o que caracterizou uma elevada produção de biogás.

As perdas na produção de biogás foram influenciadas pelo sistema de armazenamento por deslocamento líquido. O referido sistema apresentou acentuadas variações na pressão e temperatura, além da dissolução do biogás normalmente ocorrer no líquido efluente.

A metodologia teórica aplicada no cálculo da produtividade do gás metano mostrou-se válida como parâmetro de controle no monitoramento do sistema de tratamento, juntamente com outros mecanismos de avaliação físicos, físico-químicos e biológicos.

A pesquisa demonstrou ainda que existe enorme viabilidade técnica em se obter energia por meio do tratamento de dejetos de suínos, especialmente em comunidades rurais.

\section{REFERÊNCIAS BIBLIOGRÁFICAS}

AMERICAN PUBLIC HEALTH ASSOCIATION. Standard methods for the examination of water and wastewater. 20. ed. New York, 1998. 1134 p.

ASSOCIAÇÃO BRASILEIRA DAS INDUSTRIAS PRODUTORAS EEXPORTADORAS DECARNE SUÍNA. São Paulo, 2002. Disponível em: <http// www.abipecs.com.br/histprodução.aps $>$. Acesso em: 10 fev. 2004.
CAMPOS, C. M. M. Physical aspects affecting granulations in UASB reactors. 1990. $459 \mathrm{f}$. Thesis (Ph.D) - Universidade de Newcastle upon Tyne, Newcastle, 1990.

CAMPOS, C. M. M. Reatores anaeróbios de última geração. Lavras: UFLA, 1998.59 p. Apostila.

CAMPOS, C. M. M.; HARDOIM, P. C.; BOTELHO, C. G.; SEVERO, J. C. A. Programa computacional para simulação e dimensionamento de sistemas de tratamento de dejetos suínos. In: CONGRESSO BRASILEIRODEENGENHARIA AGRÍCOLA (CONBEA), 28., 1999, Pelotas, RS. Anais... Pelotas: SBEA, 1999. p. 165.

CAMPOS, C. M. M.; LUIZ, F. A. R.; FIGUEIREDO, J. G.; SALEH, B. B. Avaliação do desempenho de um sistema anaeróbio em bancada tratando leite diluído simulando efluente de laticínio In: CONGRESSO BRASILEIRO DE ENGENHARIAAGRÍCOLA(CONBEA), 32., 2003, Goiânia, GO. Anais... Goiânia: Novas Fronteiras, 2003.

CAMPOS, J. R. Tratamento de gases gerados em reatores anaeróbios. In: . Tratamento de esgotos sanitários por processo anaeróbio e disposição controlada no solo. Rio de Janeiro: ABES/PROSAB, 1999. cap. 10, p. 249-270, 435 p.

CHERNICHARO, C. A. de L. Reatores anaeróbios. Belo Horizonte: UFMG, 1997. 246 p.

CONAMA. Resoluções Conama 1984 à 1990. 3. ed. Brasília: Ibama, 1990. 
HAANDEL, A. C. van; LETTINGA, G. Tratamento anaeróbio de esgotos: um manual de para regiões de clima quente. Campina Grande: Epgraf, 1994.

KONZEN, E. A. Manejo e utilização dos dejetos suínos. Concórdia: EMBRAPA-CNPSA, 1983. 32 p. (Circular técnica, 6).

METCALF; EDDY. Wastewater engineering treatment, disposal, reuse. 3. ed. New York: McGraw-Hill, 1955.1334 p.

OLIVEIRA, P. A. V. de (Coord.). Manual de manejo e utilização dos dejetos de suínos. Concórdia: EMBRAPACNPSA, 1993. 188 p. (Documentos, 27).
OLIVEIRA, R. A. de. Efeito da concentração de sólidos suspensos do afluente no desempenho e característica do lodo de reatores anaeróbios de fluxo ascendente com manta de lodo tratando águas residuárias de suinocultura. 1997. 359 f. Tese (Doutorado em Engenharia Civil, Área de Concentração Hidráulica e Saneamento) - Escola de Engenharia de São Carlos, Universidade de São Paulo, São Carlos, 1997.

SILVA, F. M. Utilização do biogás como combustível. In: CONGRESSO BRASILEIRO DE ENGENHARIA AGRÍCOLA, 27., 1998, Lavras. Anais... Lavras: UFLA/ SBEA, 1998. p. 96-125. 